\title{
Design of Photoaffinity Probe Molecules for Identification and Modification of Target Proteins
}

\author{
Hiroyuki Nakamura、 * Hyun Seung Ban, ${ }^{\ddagger}$ Kazuki Shimizu, ${ }^{*}$ Hidemitsu Minegishi and Shinichi Sato
}

Chemical Resources Laboratory, Tokyo Institute of Technology, Yokohama, 226-8503, Japan

${ }^{*}$ Department of Chemistry, Faculty of Science, Gakushuin University, Tokyo, 171-8588, Japan

Techniques for the visualization of target proteins by small-molecule probes in living systems are highly important to investigate the function, dynamics, localization, and crosstalk of individual proteins. We have studied inhibitors of hypoxia-inducible factors (HIF), which are heterodimeric $(\alpha / \beta)$ transcriptional factors and major physiological stimuli for expression of angiogenesis factors. Inhibition of tumor-induced angiogenesis prevents growth of many types of solid tumors, thus is considered to provide a novel approach for cancer treatment. We recently developed carborane-containing phenoxyacetanilides as potent inhibitors of HIF-1 $\alpha$ activation under hypoxia. We designed their photoaffinity labeling molecules to clarify the action mechanism against the HIF inhibition. Using the photoaffinity labeling molecules, we identified that heat shock protein (HSP) 60 is the target protein and clarified that HSP60 has an important role for stabilization of HIF-1 $\alpha$ under hypoxia.

Keywords: photoaffinity, protein, benzophenone,click reaction

\section{Introduction}

Hypoxic regions of solid tumors are common occurrences, and the extent of tumor hypoxia is associated with tumor angiogenesis, proliferation, invasion, and metastasis. The hypoxia-inducible factor (HIF) is a basic helix-loop-helix heterodimeric transcription factor that regulates tumor cell adaptation and survival under hypoxic conditions. HIF-1 is a heterodimeric complex that consists of a hypoxia-inducible HIF-1 $\alpha$ subunit and constitutively expressed HIF-1 $\beta$ subunit.[1] Under aerobic conditions, HIF- $1 \alpha$ is rapidly degraded via a $26 \mathrm{~S}$ proteasome-dependent pathway, whereas under hypoxic conditions, HIF-1 $\alpha$ is stabilized and translocated into the nucleus where it forms a heterodimeric complex with HIF- $1 \beta$ and binds to hypoxia response elements (HREs) in the promoter of hypoxia-responsive genes such as vascular endothelial growth factor, insulin-like growth factor, heme oxygenase-1, and inducible nitric oxide synthase.[2] HIF-1 $\alpha$ is found at increased levels in many types of human tumors relative to normal tissues, and overexpression of HIF-1 $\alpha$ correlates with poor prognosis and resistance to treatment for cancer patients.[3] Therefore, HIF-1 $\alpha$ has been considered a potential target for antitumor agents.

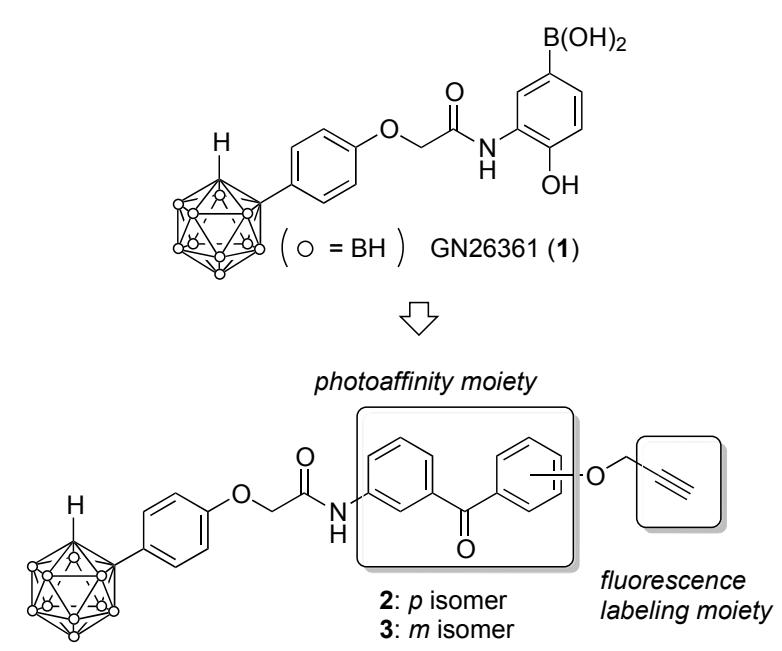

Fig. 1. Structures of GN26361 (1) and our design of the photoaffinity labeling probes $\mathbf{2}$ and $\mathbf{3}$.

We have studied boron-based drug design. A stable B-H-B three-center two-electron bond results in the formation of various stable boron clusters. In particular, carboranes (icosahedral dicarba-closo-dodecaboranes; $\mathrm{C}_{2} \mathrm{~B}_{10} \mathrm{H}_{12}$ ) possess remarkable thermal and catabolic stability,[4] and their icosahedral geometry and exceptional 
hydrophobicity have been used as hydrophobic pharmacophores in biologically active molecules interacting with their target proteins.[5] Recently, we reported that carboranylphenoxyacetanilide GN26361 (1) induced degradation of HIF-1 $\alpha$ protein under hypoxic conditions. [6, 7] In this paper, we described a design of photoaffinity probe molecules for identification of a target protein to clarify the action mechanism of $\mathbf{1}$ against HIF inhibition.

\section{Method}

2.1. Design of photoaffinity probe molecules

Much attention has been focused on a chemical biology technique for detecting target proteins of biologically active molecules having undefined action mechanisms. Especially, photoaffinity labeling technique is important for a covalent bond formation between the ligand small molecule and the target protein. Our design of multifunctional molecular probes of $\mathbf{1}$ is shown in Figure 1.

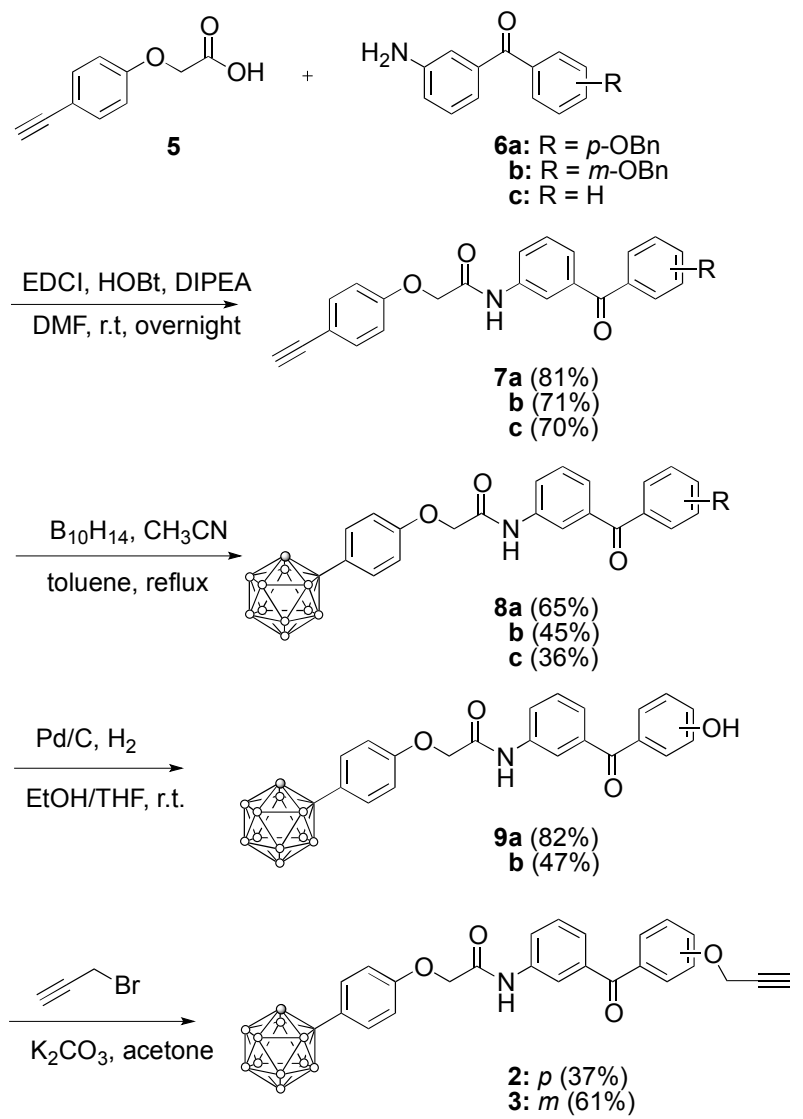

Fig. 2. Synthetic scheme of the photoaffinity labelling probes $\mathbf{2}$ and $\mathbf{3}$.
We included two important functions in the probe molecules: a benzophenone moiety as a photoaffinity labeling function to form covalent binding with a target protein by UV[8] and an acetylene moiety to conjugate with azide-linked fluorescence by click reaction for identification of a target protein.[9]

Synthesis of the photoaffinity labeling probes $\mathbf{2}$ and $\mathbf{3}$ is shown in Fig. 2. The reaction of carboxylic acid 5 and aniline 6 proceeded under the amide bond formation conditions using 1-Ethyl-3-(3-dimethylaminopropyl)carbodiimide (EDCI), 1-hydroxybenzotriazole (HOBt), and diisopropylethyamine (DIPEA) in $N, N$-dimethylformamide (DMF) at room temperature to give 7a-c in $70-81 \%$ yields. Decaborane coupling was carried out using acetonitrile as a Lewis base under toluene refluxed conditions to give the corresponding carboranes 8a-c in $36-65 \%$ yields. The benzyl groups of carboranes $\mathbf{8 a}$ and $\mathbf{8 b}$ were removed by hydrogenesis in the presence of palladium catalyst and the resulting phonolic hydroxyl group reacted with propargylbromide under the basic condition and the photoaffinity labeling probes $\mathbf{2}$ and $\mathbf{3}$ were obtained in 37 and $61 \%$ yields, respectively.

\subsection{Cell Culture}

The cells were cultured at $37^{\circ} \mathrm{C}$ under $5 \% \mathrm{CO}_{2}$ atmosphere in RPMI 1640 medium (Wako Pure Chemicals, Osaka, Japan) supplemented with $10 \%$ fetal bovine serum (FBS, HyClone, Logan, UT), $100 \mathrm{U} / \mathrm{ml}$ penicillin, and $100 \mu \mathrm{g} / \mathrm{ml}$ streptomycin (Invitrogen, Carlsbad, CA). For subsequent experiments, the cells were seeded at a density of 2 $\mathrm{x} 10^{5} \mathrm{cells} / \mathrm{ml} /$ well in a 12 -well TC plate, and incubated at $37^{\circ} \mathrm{C}$ for $20 \mathrm{~h}$. Hypoxic condition was achieved by replacing cells to $1 \% \mathrm{O}_{2}, 94 \% \mathrm{~N}_{2}$, and $5 \% \mathrm{CO}_{2}$ in a multigas incubator.

\subsection{Immunoblotting and immunoprecipitation}

After drug treatment for $4 \mathrm{~h}$, the cells were washed three times with phosphate buffered saline (PBS, $\mathrm{Ca} / \mathrm{Mg}$-free), dipped in $100 \mu \mathrm{l}$ of ice-cold lysis buffer (20 mM, 4-(2-hydroxyl)-1piperazineethanesulfonic acid (HEPES), $\mathrm{pH}$ 7.4, $1 \%$ Triton X-100, 10\% glycerol, $1 \mathrm{mM}$ ethylenediaminetetraacetic acid (EDTA), $5 \mathrm{mM}$ sodium fluoride, $2.5 \mathrm{mM} \quad p$-nitrophenylene 
phosphate, $10 \mu \mathrm{g} / \mathrm{ml}$ phenylmethylsulfonylfluoride, $1 \mathrm{mM}$ sodium vanadate, and $10 \mu \mathrm{g} / \mathrm{ml}$ leupeptin) for $15 \mathrm{~min}$, and disrupted with a Handy Sonic Disrupter, and the lysate was boiled for 5 min in a sample buffer $(50 \mathrm{mM}$ Tris, $\mathrm{pH} 7.4,4 \%$ sodium dodecyl sulphate (SDS), $10 \%$ glycerol, $4 \%$ 2-thioethanol, and $50 \mu \mathrm{g} / \mathrm{ml}$ bromophenol blue) at a ratio of $4: 1$. The cell lysates were subjected to SDS-polyacrylamide gel electrophoresis (PAGE), transferred to polyvinylidene difluoride (PVDF) membrane (GE Healthcare, Buckinghamshire, UK), and immunoblotted with anti-HIF-1 $\alpha$ antibody and anti-HIF-1 $\beta$ antibody (BD Transduction Laboratories, Lexington, KY). After further incubation with horseradish peroxidase (HRP)-conjugated secondary antibody, the blot was treated with ECL kit (GE Healthcare) and protein expression was visualized with a Molecular Imager ChemiDoc XRS System (Bio-Rad, Hercules, CA). For immunoprecipitation, HeLa cells $\left(2 \times 10^{6}\right.$ cells $)$ were dipped in $500 \mu \mathrm{l}$ of ice-cold lysis buffer for 30 min at $4^{\circ} \mathrm{C}$. The lysis buffer containing the cells was centrifuged for $20 \mathrm{~min}$ at $13,200 \mathrm{rpm}$ and $4^{\circ} \mathrm{C}$, and the supernatant obtained was incubated overnight at $4^{\circ} \mathrm{C}$ with primary antibody $(2 \mu \mathrm{g})$ with $20 \mu \mathrm{l}$ Protein A/G plus-Agarose (Santa Cruz Biotechnology, Santa Cruz, CA).

\subsection{Reporter-gene assay}

HeLa cells expressing hypoxia response element (HRE)-dependent luciferase reporter construct (HRE-Luc) were established with Cignal $^{\mathrm{TM}}$ Lenti Reporter (SABiosciences, Frederick, MD) according to the manufacturer's instructions. The consensus sequence of HRE was 5'-TACGTGCT-3' from erythropoietin gene. Cells stably expressing the HRE-reporter gene were selected with puromycin. The cells were incubated for $12 \mathrm{~h}$ with or without drugs under the normoxic or hypoxic condition. After removal of the supernatant, the luciferase assay was performed using a Luciferase Assay System (Promega Corp., Madison, WI) according to the manufacturer's instructions.

2.5. Photoaffinity labeling, click chemistry, and fluorescent gel imaging

Soluble extract of HeLa cells was prepared using glass beads disruption in lysis buffer by centrifugation at $13,200 \mathrm{rpm}$ for $20 \mathrm{~min}$. The cell lysate $(200 \mu \mathrm{g})$ or recombinant human heat shock protein (HSP) 60 protein $(2 \mu \mathrm{g}$, Assay Designs, Ann Arbor, MI) were incubated for $10 \mathrm{~min}$ at $4^{\circ} \mathrm{C}$ with various concentrations of probe ( 2 or $\mathbf{3})$ in the presence or absence of $\mathbf{1}$, and then irradiated with $360 \mathrm{~nm}$ UV light (longwave ultraviolet lamp model B-100A, UVP, Upland, CA) on ice for $30 \mathrm{~min}$. Click reactions (Invitrogen) were established with Click-iT Protein Reaction Buffer Kit (Invitrogen) according to the manufacturer's instructions. After the click reaction, proteins were precipitated with methanol/chloroform/water $(60 / 15 / 40, \quad \mathrm{v} / \mathrm{v})$ and denatured by boiling for $5 \mathrm{~min}$ in a sample buffer. Proteins were separated by SDS-PAGE, and fluorescence of Alexa Fluor 488 was visualized in-gel using a Molecular Imager ChemiDoc XRS System.

2.6. Two-dimensional electrophoresis and proteomics

The dehydration of immobilized $\mathrm{pH}$ gradient (IPG) strips (Immobiline DryStrip, pH 3-10, $7 \mathrm{~cm}$, GE Healthcare) was performed for $12 \mathrm{~h}$ in dehydration buffer $(8 \quad \mathrm{M}$ urea, $2 \%$ 3-[cholamidopropyl]dimethylamino)-1-propanesulf onate CHAPS), $18 \mathrm{mM}$ dithiothreitol (DTT), 2\% IPG buffer (GE Healthcare), and $50 \mu \mathrm{g} / \mathrm{ml}$ bromophenol blue) containing the probe-labeled protein. Isoelectric focusing was carried out as follows; $300 \mathrm{~V}$ for $4 \mathrm{~h}, 1000 \mathrm{~V}$ for $30 \mathrm{~min}, 5000 \mathrm{~V}$ for $80 \mathrm{~min}$, and $5000 \mathrm{~V}$ for $25 \mathrm{~min}$ using the Ettan IPGphor 3 (GE Healthcare). The IPG strips were incubated for $15 \mathrm{~min}$ in equilibration buffer I (50 $\mathrm{mM}$ Tris- $\mathrm{HCl}, \mathrm{pH} 8.8$ containing $2 \%$ SDS, $6 \mathrm{M}$ urea, 30\% glycerol and 1\% DTT) followed by equilibration buffer II (2\% SDS, $6 \mathrm{M}$ urea, 30\% glycerol and $2.5 \%$ iodoacetamide in $50 \mathrm{mM}$ Tris- $\mathrm{HCl}, \mathrm{pH} 8.8$ ) for $15 \mathrm{~min}$. The strips were then transferred to $12 \%$ polyacrylamide gel and electrophoresis was performed at $125 \mathrm{~V}$. After visualization of Alexa Fluor 488 fluorescence, the gel was stained with coomassie brilliant blue (CBB). The Alexa Fluor 488 fluorescence-visualized and CBB-stained spots were excised from the gel, reduced with $10 \mathrm{mM}$ DTT, alkylated with $55 \mathrm{mM}$ iodoacetamide, and trypsinized for $8 \mathrm{~h}$ at $37^{\circ} \mathrm{C}$. The digested peptide fragments were analyzed by liquid chromatography/electroscopy (LC/ESI-TOF MS) 
system (Bruker Daltonics, Bremen, Germany), and the peptide mass fingerprinting (PMF) was performed against SwissProt database using Mascot.

\subsection{MDH refolding assay}

The chaperone activity of HSP60 was determined using malate dehydrogenase from porcine heart $(\mathrm{MDH}$, Sigma). Denaturation of $\mathrm{MDH}(17.1 \mu \mathrm{M})$ was performed for $2 \mathrm{~h}$ at $25^{\circ} \mathrm{C}$ in $10 \mathrm{mM} \mathrm{HCl}$. A mixture of HSP60 $(4 \mu \mathrm{M})$ and HSP10 ( $8 \mu \mathrm{M}$, Assay Designs) was incubated for 90 min at $30^{\circ} \mathrm{C}$ with or without $\mathbf{1}$ or $\mathbf{4}$ in reconstitution buffer (50 mM Tris, pH 7.6, $300 \mathrm{mM} \mathrm{NaCl}, 20 \mathrm{mM}$ $\mathrm{KCl}, 20 \mathrm{mM} \mathrm{Mg}\left(\mathrm{CH}_{3} \mathrm{COO}\right)_{2}$ and $\left.4 \mathrm{mM} \mathrm{ATP}\right)$. The $\mathrm{MDH}$ folding reaction was performed in folding assay buffer $(100 \mathrm{mM}$ Tris, $\mathrm{pH}$ 7.6, $7 \mathrm{mM} \mathrm{KCl,} 7$ $\mathrm{mM} \mathrm{MgCl} 2,10 \mathrm{mM}$ DTT, and $2 \mathrm{mM}$ ATP) and final concentrations of MDH, HSP60, and HSP10 were $1.71 \mu \mathrm{M}, 1 \mu \mathrm{M}$, and $2 \mu \mathrm{M}$, respectively. After incubation for $30 \mathrm{~min}$ at $42^{\circ} \mathrm{C}$, aggregation of $\mathrm{MDH}$ was measured as the level of turbidity at $340 \mathrm{~nm}$.

\section{Results and Discussions}

3.1. Inhibitory potency of the photoaffinity labeling probes $\mathbf{2}$ and $\mathbf{3}$

We first examined inhibitory potency of the synthesized probes $\mathbf{2}$ and $\mathbf{3}$ toward HIF activity. The effects of the probes on the hypoxia-induced transcriptional activity of HIF-1 in human cervical cancer cells HeLa were examined by HRE reporter gene assay As shown in Fig. 3(a), the inhibitory effects of the photoaffinity labeling probes $\mathbf{2}$ and $\mathbf{3}$ against HIF transcriptional activity were decreased almost 10-fold compared with compound $\mathbf{1}$ and their $\mathrm{IC}_{50}$ values were 7.9 and $7.8 \mu \mathrm{M}$, respectively. We also examined immunoblot analysis of the HIF-1 $\alpha$ protein accumulation under hypoxia. As shown in Fig. 3(b), the reducing property of the probes on the HIF-1 $\alpha$ protein level was parallel to that of compound $\mathbf{1}$, and compounds $\mathbf{2}$ and $\mathbf{3}$ induced HIF- $1 \alpha$ protein degradation at a $30 \mu \mathrm{M}$ concentration. These results reveal that boronic acid in compound $\mathbf{1}$ is an efficient functional group for induction of HIF-1 $\alpha$ protein degradation. These observations are consistent with a finding similar to the results of our previous study.

3.2. Photoaffinity labeling using the photoaffinity labelling probes $\mathbf{2}$ and $\mathbf{3}$ in HeLa cell lysate.

(A)

\begin{tabular}{cc}
\hline Compound & $\begin{array}{r}\text { HRE Reporter Gene } \\
\text { Assay IC } \mathrm{C}_{50}(\mu \mathrm{M})\end{array}$ \\
\hline $\mathbf{1}$ & $0.7 \pm 0.2$ \\
$\mathbf{2}$ & $7.9 \pm 2.1$ \\
$\mathbf{3}$ & $7.8 \pm 0.2$ \\
\hline
\end{tabular}

(B)

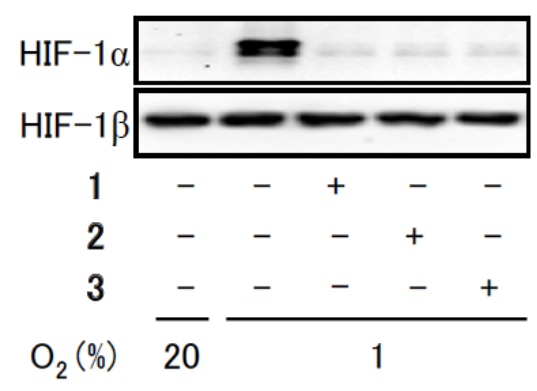

Fig. 3. HIF inhibitory activity of the probe compounds under hypoxic conditions. (A) Inhibitory effects of $\mathbf{1}$ and probes on transcriptional activity of HIF were determined by HeLa cell-based HRE reporter gene assay. (B) Effects of $1(10 \mu \mathrm{M})$ and probes $(30 \mu \mathrm{M})$ on the hypoxia-induced increase in HIF-1 $\alpha$ protein were determined by immunoblot in HeLa cells.

We examined photoaffinity labeling using the photoaffinity labelling probes $\mathbf{2}$ and $\mathbf{3}$ in HeLa cell lysate and click conjugation with Alexa Fluor 488-azide to visualize the target protein. Proteins bound to the probe-Alexa Fluor 488 were visualized by direct in-gel fluorescence detection, after sodium dodecyl sulfate polyacrylamide gel electrophoresis (SDS-PAGE). The results are shown in Fig. 4. A major fluorescent band above the $55 \mathrm{kDa}$ molecular weight marker was detected by both probes in a concentration-dependent manner, and binding of $\mathbf{3}$ with the protein was slightly more sensitive than that of $\mathbf{2}$. We performed competition assays with $\mathbf{1}$, an acetylene-free analogue of $\mathbf{2}$ and $\mathbf{3}$ in order to confirm the specificity of probe binding. Competition with 1 resulted in almost complete abrogation of the level of the fluorescent band at $\sim 55 \mathrm{kDa}$. These results raise the possibility that the band at $\sim 55 \mathrm{kDa}$ may be the main target protein of $\mathbf{1}$ and its probes. 
(A)

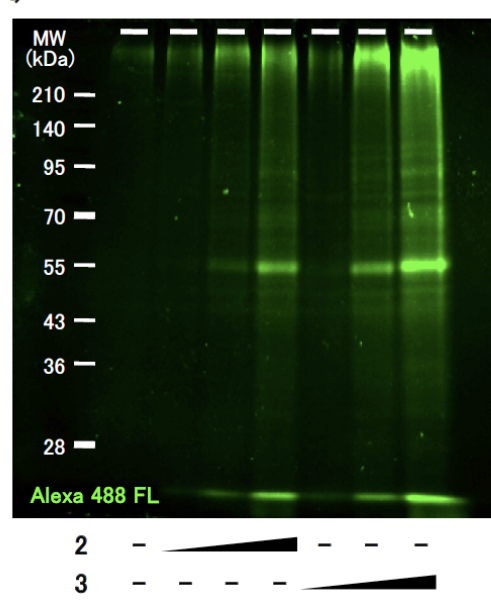

(B)

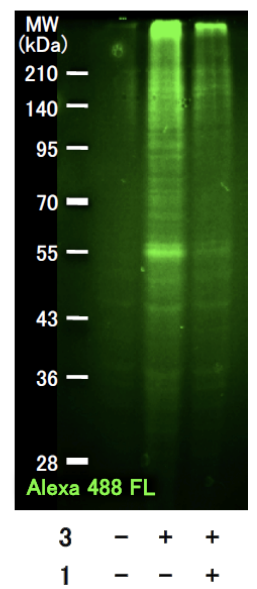

Fig. 4. Fluorescence imaging of target protein bound to the probe. (A) HeLa cell lysate was irradiated at $360 \mathrm{~nm}$ for 30 min with various concentrations $(30,100$, and 300 $\mu \mathrm{M})$ of each probe. The conjugation of probe and Alexa Fluor 488 azide was performed by click reaction. (B) Total cell lysates from HeLa cells photoaffinity-labeled with $3(100 \mu \mathrm{M})$ in the presence or absence of $1(500$ $\mu \mathrm{M})$.

We next examined two-dimensional electrophoresis followed by in-gel digestion in order to identify the protein manifest as shown in Fig. 5. Peptide mass fingerprinting analysis (PMF) was performed by liquid chromatography/ electrospray ionization time-of-flight mass spectrometry (LC/ESI-TOF MS).

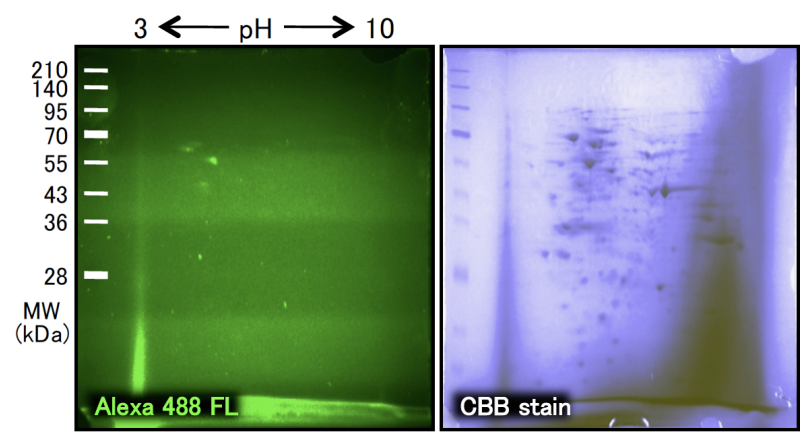

Fig. 5. Two-dimensional electrophoresis and fluorescent imaging. Alexa Fluor 488 fluorescence was visualized, and then the gel was stained with CBB.

PMF analysis searched in Mascot revealed that the protein bound to the probe was heat shock protein (HSP) 60 with a significant score value of

245 , sequence coverage of $73 \%$, and 28 peptides matching. To confirm the direct binding of $\mathbf{3}$ and HSP60, in-gel fluorescence imaging was performed with recombinant human HSP60 protein. As shown in Fig. 6, a fluorescent band was observed in the presence of 3 . Furthermore, 3 selectively bound to HSP60 in mixture of recombinant HSP60, 70, and 90.

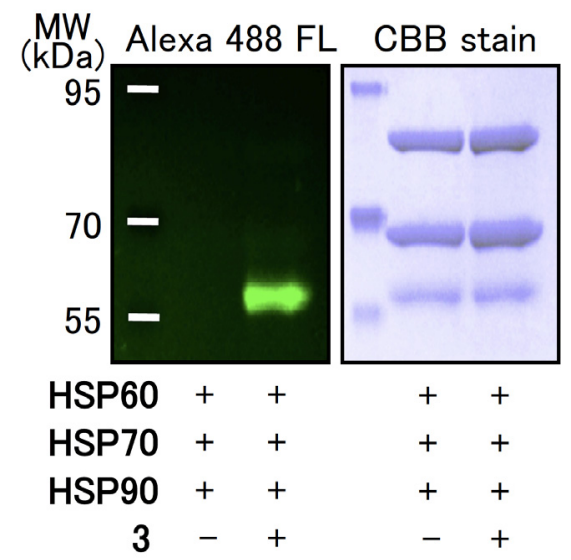

Fig. 6. Fluorescence imaging of probe-labeled recombinant HSP60. Recombinant human HSP60, HSP70, and HSP90 were irradiated with $\mathbf{3}$ and conjugated with Alexa Fluor 488-azide by click reaction.

\subsection{Inhibition of HSP60 chaperone and ATPase activity.}

It has been reported that HIF- $1 \alpha$ is one of the client proteins of molecular chaperon HSP90, and geldanamycin, a HSP90 inhibitor that stimulates HIF- $1 \alpha$ degradation by affecting folding and maturation. However, interaction of HSP60 and HIF- $1 \alpha$ has not been reported so far. Therefore, we examined the effect of compound 1 on HSP60 chaperon activity. Epolactaene is a microbial metabolite isolated from the fungal strain Penicillium sp. BM 1689-P and its tert-butyl ester (ETB) has been reported as an inhibitor of HSP60 chaperon activity. It was suggested that Cys442 is responsible for the covalent binding with ETB. Therefore, we used ETB as a positive control for the experiment of HSP60 chaperon activity. As shown in Fig. 7, compound 1 inhibited HSP60 chaperone activity similar to ETB. To our knowledge, this is the first report demonstrating the implication of HSP60 in HIF activation. 

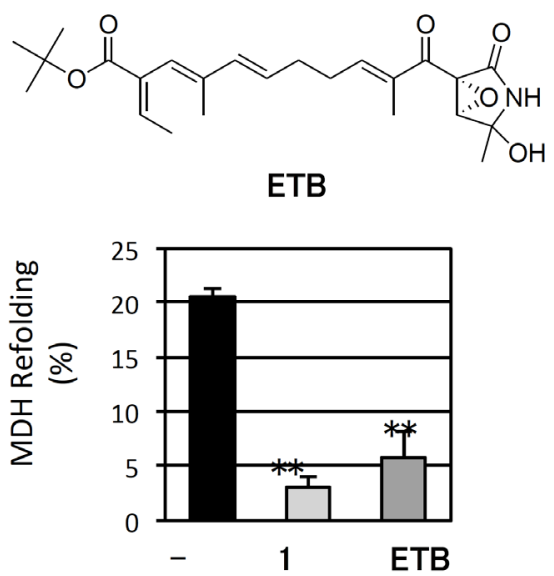

Fig. 7. Inhibition of HSP60 chaperone activity by compound $\mathbf{1}$ and ETB. Thermal aggregation of MDH was performed in the presence or absence of reconstituted HSP60 and HSP10. The level of MDH refolding by HSP60 and HSP10 was inhibited by 1 and ETB.

\section{Conclusion}

We have succeeded in identification of HSP60 as the target protein of the HIF-1 inhibitor ocarboranylphenoxyacetanilide $\mathbf{1}$ by using its multifunctional molecular probe $\mathbf{3}$ that combine photoaffinity labeling and click reaction. Although HSP90 is well known to stabilize HIF- $1 \alpha$ protein under hypoxia, we clarified that HSP60 also possesses important role for stabilization of HIF-1 $\alpha$ protein under hypoxia.

\section{Acknowledgments}

This work was supported by a Grant-in-Aid for Scientific Research on Innovative Areas "Chemical Biology of Natural Products" from The Ministry of Education, Culture, Sports, Science and Technology, Japan.

\section{References}

1. G. L. Wang, B. H. Jiang, E. A. Rue, G. L. Semenza, Proc. Nat. Acad. Sci. USA, 92 (1995) 5510.

2. G. L. Semenza, Targeting, Nat. Rev. Cancer 3 (2003) 721.

3. A. L. Harris, Nat. Rev. Cancer 2 (2002) 38.

4. R. N. Grimes, Carboranes, 2nd ed., Academic Press (Elsevier), London, 2011.

5. M. Scholz, E. Hey-Hawkins, Chem. Rev. 111 (2011) 7035.

6. K. Shimizu, M. Maruyama, Y. Yasui, H. Minegishi, H.S. Ban, H. Nakamura, Bioorg. Med. Chem. Lett. 20 (2010) 1453.

7. H. S. Ban, K. Shimizu, H. Minegishi, H. Nakamura, J. Am. Chem. Soc. 132 (2010) 11870.

8. G. Dorman, G. D. Prestwich, 33 (1994) 5661.

9. H. C. Kolb, K. B. Sharpless, Drug Discovery Today 8 (2003) 1128. 